\title{
C-FACTOR AND RESTORATION VOLUME AS DERIVATES OF COMPOSITE FILLINGS: CLINICAL SUCCESS AFTER 12 MONTHS OF MONITORING
}

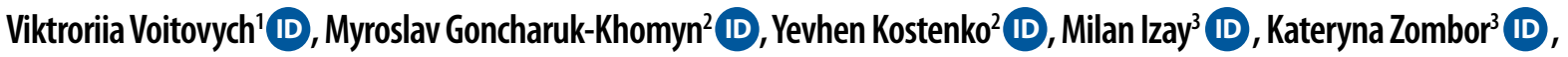 \\ Bohdan Sapovych ${ }^{3}$ (D)
}

'Department of Therapeutic Dentistry, Uzhhorod National University, Uzhhorod, Ukraine ${ }^{2}$ Department of Prosthetic Dentistry, Uzhhorod National University, Uzhhorod, Ukraine ${ }^{3}$ Department of Pediatric Dentistry, Uzhhorod National University, Uzhhorod, Ukraine

\begin{abstract}
INTRODUCTION: Relevant literature data represents high clinical success rates of direct composite restorations, even though some cavity-associated parameters remain under in vivo and in vitro research as factors associated with possible failure of restorations.

ОвјеCтIVES: To evaluate possible influence of restoration volume, configuration factor, and its' derivates on clinical success of composite fillings placed into class I and class II cavities after 12 months of monitoring.

MATERIAL AND METHODS: Design of the study was based on comparative analysis of restoration success rates registered among two groups of patients with class I and class II cavity configurations and further in-depth analysis of cavityrelated parameters. Each cavity was scanned intraorally after preparation phase and after restoration placement. Obtained scan-files were imported in *.stl format into specialized software. Calculation of exact C-factor values was provided as ratio of bonded surfaces to un-bonded surfaces, and objectified considering areas of the surfaces.

RESULTS: Correlation between C-factor parameter (as ratio of bonded surfaces to un-bonded ones) and overall level of composite direct restoration failure reached $r=0.18(p>0.05)$. Such association increased to $r=0.44(p<0.05)$ when C-factor was quantified as ratio of absolute surface area of bonded cavity walls to absolute surface area of free cavity walls. Volume of provided restorations achieved the highest level of correlation with noted clinical success rates of composite direct fillings after 12 months of service $(r=0.59 ; p<0.05)$.

ConcLusions: C-factor itself, while being evaluated clinically only without the use of laboratorial equipment and detailed calculational algorithms, could not be interpreted as dominant predictor for restoration success decrease pattern after 1-year monitoring. Volumetric cavity parameters and its derivates provide greater influence on the successful outcome of clinical parameters after 12 months of restorations functioning.
\end{abstract}

KEY WORDS: composite restoration, success rate, C-factor, restoration volume.

J Stoma 2021; 74, 4: 211-220

DOI: https://doi.org/10.5114/jos.2021.111619

\section{INTRODUCTION}

Relevant literature data represents high clinical success rates of direct composite restorations, even though some cavity-associated parameters remain under in vivo and in vitro research as factors associated with possible failure of restorations $[1,2]$. Meta-analyses of prospective studies revealed that I and II classes restorations charac-

\section{JOURNAL OF STOMATOLOGY CZASOPISMO STOMATOLOGICZNE}

ADDRESS FOR CORRESPONDENCE: Myroslav Goncharuk-Khomyn, Department of Prosthetic Dentistry, Uzhhorod National University, Univesitetska St., 88000 Uzhhorod, Ukraine, e-mail: myroslav.goncharuk-khomyn@uzhnu.edu.ua

ReCEIVED: 19.01.2021 • ACCePted: 24.05.2021 • Published: 30.11 .2021 
terized with annual failure rate of $1.46 \%( \pm 1.74 \%)$ only, with slow but increasing failure tendency during prolonged periods of monitoring [3]. Considering such high success results of direct composite restorations and their financial benefit compared to indirect restorations, further in-depth analysis of factors that potentially could be related with even more improved efficiency of composite restorations seems to be reasonable and relevant [4-9].

C-factor depends on the type of cavity (as relation of bonded to un-bonded surfaces), and Kubo et al. categorized it as tooth-related factor, which influence outcome longevity of restoration success [10]. Variety of methods have been described in literature considering research aspects of polymerization kinetics and its' relation to potentially associated factors, including C-factor. Nevertheless, none of the reviewed devices or approaches were considered to be ideal for such purpose since dynamics of polymerization changes its' characterization with varying patterns [11]. On the other hand, interpretation of C-factor influence clinical restoration success, and it should be applied with caution due to stress distribution heterogenous trends, which means that positive effect of C-factor optimization in most cases could be properly evidenced only during comparison of prepared cavities with the same volumetric parameters [12]. Furthermore, every conclusion obtained during in vitro studies or approbations of analytical models should be provided with correct interpretation relevant to clinical practice. According to Opdam et al. [13], current vector of clinical studies considering present trends in restorative dentistry is specifically oriented on clinically and predictively meaningful results, contributing patients and dentists.

That is why null hypothesis of the presented study was formulated in such a way that clinical success of composite restorations placed within class I and class II cavities was not affected by $\mathrm{C}$-factor and restoration volume parameters.

\section{OBJECTIVES}

To evaluate possible influence of restoration volume, configuration factor, and its' derivates on clinical success of composite restorations placed into class I and class II cavities after 12 months of monitoring.

\section{MATERIAL AND METHODS}

\section{STUDY DESIGN AND SAMPLE'S FORMATION}

Design of the study was based on a comparative analysis of restoration success rates registered among two groups of patients with different cavity configurations (class I and class II), with further in-depth analysis of cavity-related parameters.

The present study was conducted in accordance with all provisions of the Declaration of Helsinki of World
Medical Association policy statement, and local human subjects' oversight committee guidelines and policies of the ethics committee for human and animal study of Faculty of Dentistry at Uzhhorod National University.

Initially, study sample was formed based on inclusion criteria, and included patients who were seeking dental help in University's dental clinic (Faculty of Dentistry, Uzhhorod National University, Uzhhorod, Ukraine). Inclusion criteria were as follow: 1) age of 18 years or more (in order to personally sign informed consent form to participate in the study); 2) class I or II caries lesions detected using universal diagnostic methods; 3 ) correspondence of the cavity configuration to class I or II after cavity preparation phase; 4) no potential clinical risk for pulp alteration and no need for further endodontic treatment during or after preparation phase; 5) biomechanical, functional, and clinical conditions supporting direct composite restoration, with the aim of tooth structural defect filling; 6) no clinically registered signs of present parafunctions. Exclusion criteria were classified as: 1) volume of outcome cavity (quantity of dentine and enamel loss objectified after preparation phase) that argument the need of further rehabilitation using nondirect restoration type; 2) clinical risk of possible pulp alteration occurring after cavity preparation and objectified by clinical and radiographic methods, which validated the need of root canal treatment; 3) extend of cavity configuration above class I or II after finishing preparation phase due to the caries spread or because of functional/ biomechanical need for optimizing conditions of direct restoration service.

Considering all of the above-mentioned inclusion and exclusion criteria, a sample of 61 dental patients was formed who needed and received direct composite restoration of class I or II cavities. Only one cavity/ restoration was analyzed per one study subject. Distribution of study subjects was presented considering type of cavity, including 37 patients $(60.66 \%)$ who received class I direct composite restorations (C-factor 5 group) and 24 patients (39.34\%) who obtained class II composite restorations (C-factor 2 group). Initial caries intensity parameters before cavity preparation phase among all subjects of study sample were calculated with DMF index by standard methodology [14].

\section{CLINICAL PROCEDURES}

Preparation of caries cavities was as follows: round diamond burs helped to create access points and remove affected and unsupported enamel under sufficient water irrigation, while carbide round burs were used for caries-affected dentin removal. Pear diamond burs (Komet Dental; Lemgo, Germany) served for cavity wall's straightening, removing unsupported enamel parts. Football-shaped fine burs (Komet Dental; Lemgo, Germany) were used for cavity margins beveling. Caries marker, Red Detector (Cerkamed; Stalowa Wola, Poland) 
was used for caries' identification and assurance of total caries removal during the preparation. Caries dye was firmly washed out under water flow and removed by applying cotton ball wetted with $96 \%$ ethanol.

Caries cavity preparations and direct restorations were provided by the same dental clinician for all study subjects in University's dental clinic (Faculty of Dentistry, Uzhhorod National University, Uzhhorod, Ukraine). Composite restorations were made of Estelite ASTERIA composite material (Tokuyama Dental Corporation; Tokyo, Japan) with OptiBond FL (Kerr Corporation; Orange, CA, USA) as adhesive agent according to manufacturers' instructions. Placement of direct restoration was done by oblique layering technique using different shades of material for dentine and enamel restoration $[15,16]$. Final contouring, finishing, and polishing were conducted according to manufacturers' instructions [17, 18]. Competency of the dentist who provided composite restorations was determined by his previous participation in associated epidemiological studies, targeted specialization, and calibration during corresponding research program.

\section{EVALUATION OF RESTORATIONS}

Clinical evaluation of restoration success parameters after 12 months of functioning was provided by modified USPHS criteria under control of two independent previously calibrated experts (dental specialists from the Scientific and Research Centre of Forensic Odontology who are members of the Association of Forensic Dentistry in Ukraine and IOFOS), none of which participated in the restoration placement [19].

\section{DIGITALIZATION OF CAVITIES AND RESTORATIONS}

After preparation phase, each analyzed cavity was scanned intra-orally using Medit i500 scanner (MEDIT
Corp.; Seoul, Korea), with trueness (accuracy) of $5.1 \mu \mathrm{m}$ $( \pm 0.49 \mu \mathrm{m})$ and precision (consistency) of $3.2 \mu \mathrm{m}$ $( \pm 0.74 \mu \mathrm{m})$ according to provided manufacturer's specifications [20]. Second scanning procedure was performed right after restoration placement. Each scan-file obtained was converted to *.stl format and imported into Autodesk Meshmixer software (Autodesk Inc.; San Rafael, CA, USA) [21]. Files obtained after restoration placement were analyzed with further exact volume calculation using 'analysis-stability' function of the above-mentioned software, which helped to represent targeted parameter in $\mathrm{mm}^{3}$. The same procedure was applied with files obtained right after preparation phase before composite restoration placement (Figure 1). Mathematical difference in volume parameters between analyzed meshes acquired after preparation phase and after restoration placement, represented the volume of placed direct composite restoration.

\section{C-FACTOR ANALYSIS}

Calculation of the exact C-factors' values was provided as previously described ratio of bonded surfaces amount to un-bonded surfaces amount, and objectified using Autodesk Meshmixer software (Autodesk Inc.; San Rafael, CA, USA) [22, 23]. Surface area of cavity walls was calculated via their extraction in Autodesk Meshmixer software (Autodesk Inc., San Rafael, CA, USA) and further use of 'analysis-stability' function, which helped to represent targeted parameters in $\mathrm{mm}^{2}$ (Figure 2).

Evaluations of C-factor's derivates, such as height, width, and depth of the cavity were also provided, considering their possible relationship with clinical success results of direct composite restorations. Height of the cavity was determined as a maximum dimension from the most coronal part of cavity enamel edge to the deepest point of cavity floor by straight line on the coronal plane. Width of the cavity was calculated as a maximum linear value in the axial plane oriented to the volume of the cavity. Depth

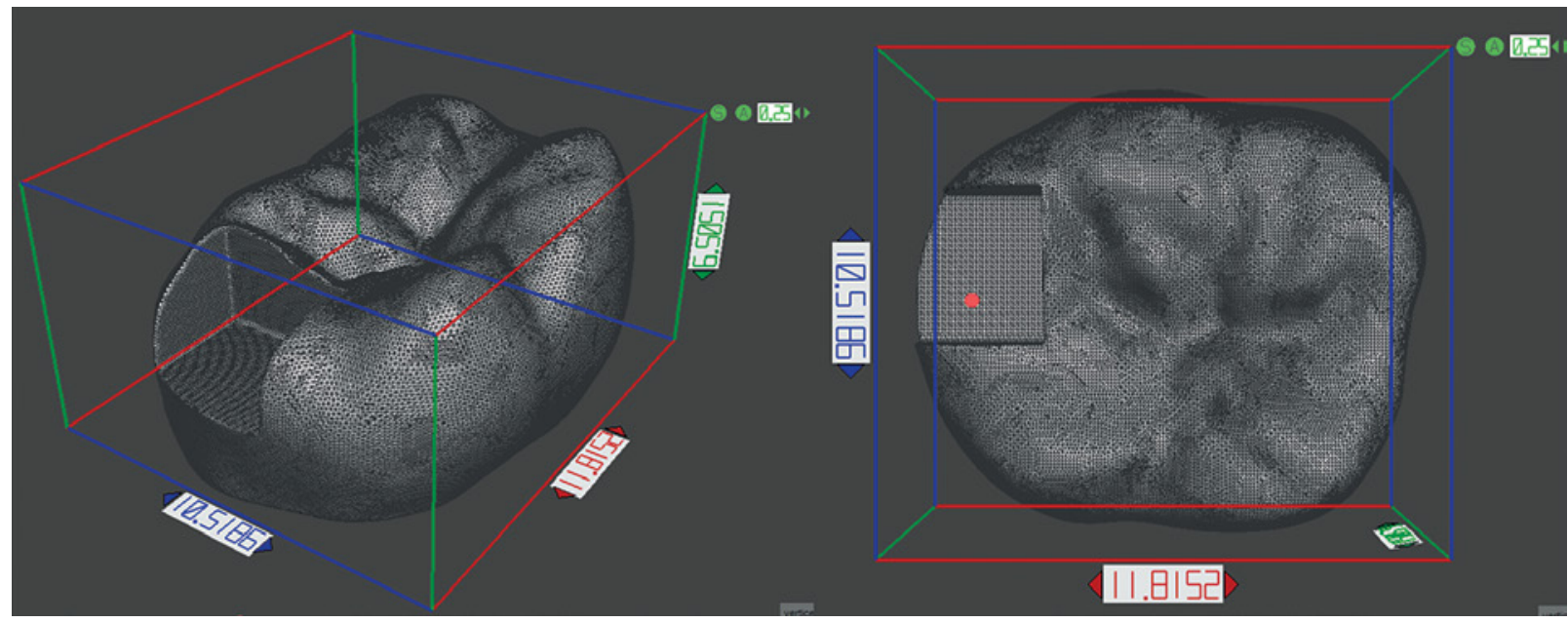

FIGURE 1. Schematic layout of tooth-scan imported into adaptive software after preparation phase 

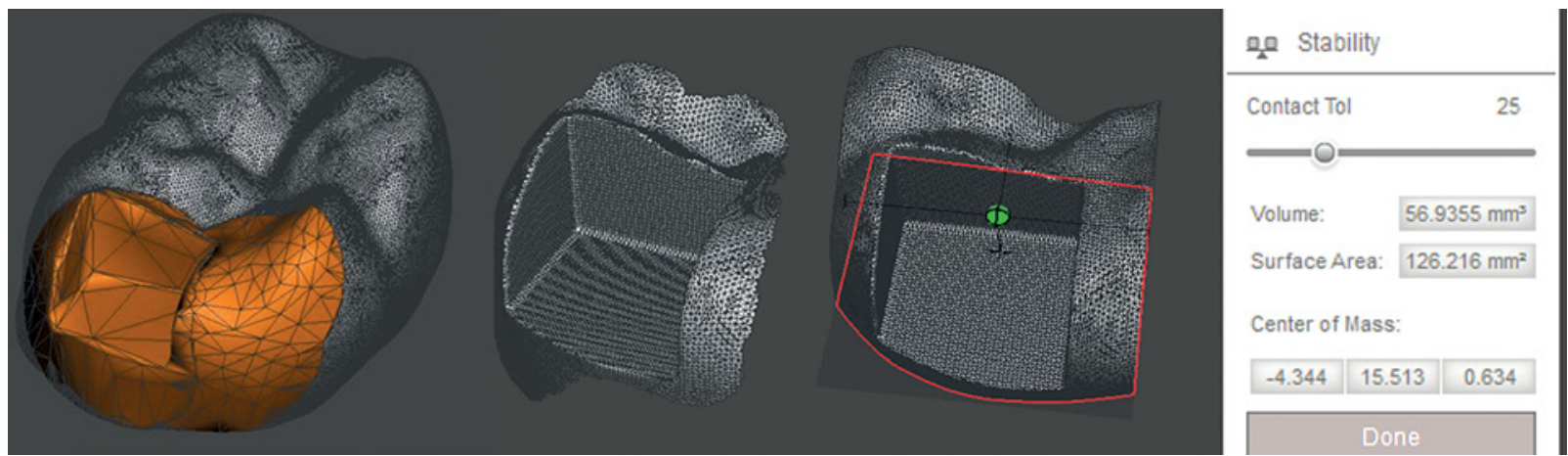

FIGURE 2. Schematic layout of measuring surface area of the cavity in adapted software

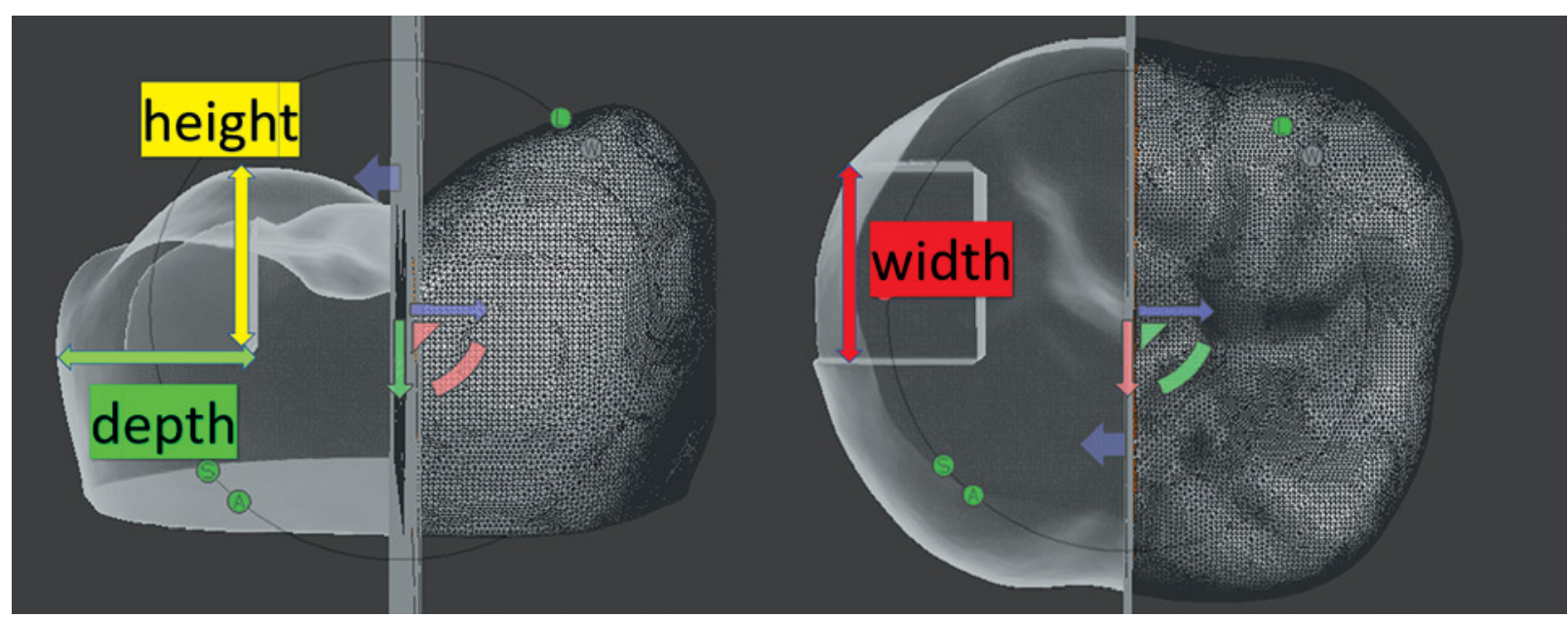

FIGURE 3. Schematic layout of measuring height, width and depth parameters of the cavity based on obtained digital scan of the tooth at adapted software

of the cavity was measured as a maximum dimension from the edge of cavity to the deepest point of the cavity floor/wall in sagittal plane (Figure 3).

\section{STATISTICAL ANALYSIS}

Descriptive statistics was used for the description of class I and II cavities groups, with a quantitative assessments of parameters, such as mean cavity surface area, range of restoration volume, mean height, mean width, and mean depth of prepared cavity and their standard deviations (SD) [24]. Levels of association between direct composite success values, restoration volume, C-factor, and its' geometrical derivates were estimated using Pearson's correlation criteria, with $p$-value $<0.05$ considered as statistically significant. Linear regression analysis was done considering potential relations between direct composite restoration success and patient-associated parameter, including age, gender, tooth type, and caries intensity [25]. Significance of statistical difference among studied parameters between group of class I cavities and group of class II cavities was measured using t-criterion. Numerical data clustering with its' further structuration and tabulation was performed via Microsoft Office 2019 software package (Microsoft; Redmond, WA, USA) [25].

\section{RESULTS}

Distribution of class I and II cavities with C-factor 5 and C-factor 2, respectively, among all study subjects considering gender, age, and caries intensity parameters are presented in Table 1.

No statistical difference due to distribution pattern considering parameters of gender and caries intensity was registered among analyzed C-factor 5 group and C-factor 2 group $(p>0.05)$; the only noted statistical difference was distribution between groups with the age parameter $(p<0.05)$.

Statistically significant difference was found between initial C-factor parameters, objectified by the ratio of exact surface area of bonded cavity walls to the area of free restoration walls within the two compared groups of C-factor 5 and $\mathrm{C}$-factor $2(p<0.05)$. Objectified values of $\mathrm{C}$-factor exceeding $\mathrm{C}$-factor values were obtained just by a quantity ratio of bonded and free surfaces, without considering specific area of these surfaces in $\mathrm{mm}^{2}$. In $\mathrm{C}$-factor 2 group, registered values of $\mathrm{C}$-factor with con- 
sideration of exact surfaces area ratio were statistically higher compared to values obtained with consideration of surfaces quantity only $(p<0.05)$.

Outcome volumes of teeth registered after restoration placement was analogical in groups of $\mathrm{C}$-factor 5 and C-factor 2 , respectively $(p>0.05)$. Similar absence of statistical difference was noted also regarding pre-restoration volumes of teeth $(p>0.05)$, mean values of which reached $417.96 \pm 30.25 \mathrm{~mm}^{3}$ in C-factor 5 group and $421.32 \pm 26.18 \mathrm{~mm}^{3}$ in $\mathrm{C}$-factor 2 group, respectively (Table 2 ).

Registered differences of retention, marginal discoloration, marginal adaptation, secondary caries, anatomic form, and surface texture between compared groups with $\mathrm{C}$-factor 5 and $\mathrm{C}$-factor 2 were not statistically significant after 12 months of restorations service $(p>0.05)$. Moreover, absolute values of USPHS criteria within C-factor 2 group were slightly lower compared to C-factor 5 group, which could be interpreted as factual, but not statistically significant lower level of clinical success (Tables 3 and 4).

The mean 12-month success rate for C-factor 5 restorations (class I) was $86.48 \pm 4.46 \%$, while for C-factor 2 (class II), it reached $83.33 \pm 3.89 \%$.

Correlation between $\mathrm{C}$-factor parameter (as ratio of bonded surfaces to un-bonded ones) and overall level of composite direct restoration failure was $r=0.18$ $(p>0.05)$, while such association increased to $r=0.44$ $(p<0.05)$ when $\mathrm{C}$-factor was quantified as a ratio of absolute surface area of bonded cavity walls to absolute surface area of free cavity walls. Even though the detailed quantified C-factor parameter demonstrated higher level of correlation with possibility of restoration reaching unsuccessful results by some USPHS parameters after 12 months of functioning, such correlation remained low, and based on outcomes of C-factor could not be considered as statistically validated parameter for direct restoration success prognosis (Tables 5 and 6).

Despite the fact that C-factor demonstrated low statistical associations with restoration success, its' geometrical derivates in the means of depth of cavity and the height of cavity were characterized with correlation values of $r=0.49(p<0.05)$ and $r=0.52(p<0.05)$, respectively. Correlation with the width of restorations appeared not to be an influential factor on the restoration success in the obtained statistical results $(p>0.05)$. The volume
TABLE 1. Distribution of classes I and II cavities of study subjects, considering gender, age, and caries intensity parameters

\begin{tabular}{|l|c|c|}
\hline \multicolumn{3}{|c|}{$\begin{array}{c}\text { Class I } \\
\text { (C-factor 5 group) }\end{array}$} \\
$\begin{array}{l}\text { Gender, } n(\%) \\
\text { (C-factor 2 group) }\end{array}$ \\
\hline Male & $16(43.24)$ & $12(50.00)$ \\
\hline Female & $21(56.76)$ & $12(50.00)$ \\
\hline Age, years \\
\hline $20-24$ & $14(37.84)$ & $7(29.17)$ \\
\hline $25-29$ & $13(35.14)$ & $12(50.00)$ \\
\hline $30-34$ & $10(27.03)$ & $5(20.83)$ \\
\hline Caries intensity, $n(\%)$ & & \\
\hline Low & $9(24.32)$ & $6(25.00)$ \\
\hline Moderate & $13(35.14)$ & $8(33.33)$ \\
\hline High & $15(40.54)$ & $10(41.67)$ \\
\hline
\end{tabular}

of provided restorations reached its' highest level of correlation among all studied parameters due to observed clinical success rates of composite direct restorations after 12 months of service, which was represented by Pearson value of $r=0.59(p<0.05)$.

No statistically validated dependencies approved by provided regression analysis were found between the age parameter $(p>0.05)$, type of tooth $(p>0.05)$, and gender $(p>0.05)$, and the obtained direct composite restoration success results after 1 year of monitoring, while linear correlation was significant between the latter and mean caries intensity levels (low, $r=0.49, p<0.05$; moderate, $r=0.25, p<0.05$; high, $r=-0.38, p<0.05)$ registered during primary diagnostic procedures (Table 7 ).

\section{DISCUSSION}

The null hypothesis, which stated that clinical success of composite restorations placed within class I and class II cavities was not affected by restoration volume and C-factor parameters, could be accepted but considering its' further revision, since due to the obtained results we could presume that restoration volume's and C-factor's derivates, such as quantity of used composite and geometrical parameters of the prepared cavity, showed statistically ap-

TABLE 2. Comparison of tooth-, cavity- and C-factor-associated parameters between C-factor 5 and C-factor 2 groups

\begin{tabular}{|c|c|c|c|}
\hline Parameters & $\begin{array}{c}\text { C-factor } 5 \\
(n=37)\end{array}$ & $\begin{array}{c}\text { C-factor } 2 \\
(n=24)\end{array}$ & $p$-value \\
\hline Cavity surface area $\left(\mathrm{mm}^{2}\right)$ & $49.57 \pm 13.14$ & $51.61 \pm 15.57$ & $>0.05$ \\
\hline C-factor quantified by the ratio of surface areas & $5.26 \pm 1.12$ & $2.83 \pm 0.87$ & $<0.05$ \\
\hline Volume of the tooth before restoration $\left(\mathrm{mm}^{3}\right)$ & $417.96 \pm 30.25$ & $421.32 \pm 26.18$ & $>0.05$ \\
\hline Volume of the tooth after restoration $\left(\mathrm{mm}^{3}\right)$ & $457.72 \pm 34.74$ & $469.83 \pm 39.56$ & $>0.05$ \\
\hline
\end{tabular}


TABLE 3. Distribution of USPHS parameters, such as retention, marginal discoloration, and marginal adaptation between C-factor 5 and C-factor 2 groups

\begin{tabular}{|l|c|c|c|}
\hline \multicolumn{1}{l}{ Parameter } & $\begin{array}{c}\text { Retention } \\
\text { abs./\% }\end{array}$ & $\begin{array}{c}\text { Marginal discoloration } \\
\text { abs./\% }\end{array}$ & $\begin{array}{c}\text { Marginal adaptation } \\
\text { abs./\% }\end{array}$ \\
\hline \begin{tabular}{l} 
C-factor 5 (class I) \\
\hline Alfa
\end{tabular} & $35 / 94.59$ & $29 / 78.38$ & $30 / 81.08$ \\
\hline Bravo & $2 / 5.41$ & $5 / 13.51$ & $6 / 16.22$ \\
\hline Charlie & $0 / 0.0$ & $3 / 8.11$ & $1 / 2.70$ \\
\hline C-factor 2 (class II) & \multicolumn{3}{|c|}{} \\
\hline Alfa & $22 / 91.67$ & $18 / 75.00$ & $19 / 79.17$ \\
\hline Bravo & $2 / 8.33$ & $4 / 16.67$ & $4 / 16.67$ \\
\hline Charlie & $0 / 0.0$ & $2 / 8.33$ & $1 / 4.17$ \\
\hline
\end{tabular}

TABLE 4. Distribution of USPHS parameters, such as secondary caries, anatomic form, and surface texture between C-factor 5 and C-factor 2 groups

\begin{tabular}{|l|c|c|c|}
\hline \multicolumn{1}{l}{ Parameter } & $\begin{array}{c}\text { Secondary caries } \\
\text { (abs./\%) }\end{array}$ & $\begin{array}{c}\text { Anatomic form } \\
\text { (abs./\%) }\end{array}$ & $\begin{array}{c}\text { Surface texture } \\
\text { (abs./\%) }\end{array}$ \\
\hline \begin{tabular}{l} 
C-factor 5 (class I) \\
\hline Alfa
\end{tabular} & $31 / 83.78$ & $34 / 91.89$ & $33 / 89.19$ \\
\hline Bravo & $0 / 0.00$ & $3 / 8.11 \%$ & $4 / 10.81$ \\
\hline Charlie & $6 / 16.22$ & $0 / 0.00$ & $0 / 0.00$ \\
\hline C-factor 2 (class II) & & & $21 / 87.50$ \\
\hline Alfa & $19 / 79.17$ & $21 / 87.50$ & $3 / 12.50$ \\
\hline Bravo & $0 / 0.00$ & $3 / 12.50$ & $0 / 0.00$ \\
\hline Charlie & $5 / 20.83$ & $0 / 0.00$ & \\
\hline
\end{tabular}

proved impact on the outcome of direct composite restorations after 12 months of service.

Actual nature of $\mathrm{C}$-factor as ratio value between the amount of bonded and un-bonded cavity surfaces seems to be far more complex and complicated [26]. Due to recently proposed shrinkage-stress theory, C-factor could be interpreted as relation of boundary-layer thickness to overall thickness of a composite restoration [27], which potentially could influence prognosis of direct restoration success during prolonged monitoring period. In a study, Braga et al. suggested that C-factor could be interpreted as microleakage predictor, but only in comparison of composite restoration and equal volume [12]. Moreover, moderate positive correlation was found between polymerization shrinkage and gap formation among cavities with high values of C-factor (class I, C-factor $=4.2$ ) [28]. In previous studies, higher levels of $\mathrm{C}$-factor were also related with greater rates and progression of stresses, and with decreased level of composite material internal adaptation, which potentially could influence composite restoration success level $[29,30]$.

Nevertheless, even considering possible negative influence of high C-factor values on composite restoration success, results of systematic review and meta-analyses sug- gested that restoration of class I and class II cavities should be provided with direct composite restorations, since such approach is less complicated and low-cost as compared to indirect restorations [31]. Additionally, such a conclusion was independent of used material and restored tooth [31].

In the current study, overall clinical success levels of analyzed restorations were statistically less than previously described data for 12 months of service [19, 32, 33]. Such pattern could be explained by relatively high number of patients with high-intensity caries levels among both C-factor 5 group and C-factor 2 group, while high-intensity caries itself was considered a risk factor associated with direct composite restoration failure $[1,2,10,34,35]$.

Even though C-factor 5 restorations' USHPS parameters were statistically similar to those registered among C-factor 2 restorations', the exact values of clinical findings in C-factor 2 group were statistically lower, which is associated with comparatively reduced clinical success. Such tendency was also noted in various previous publications, and could be explained by more complicated mechanism of contact area restoration in contrast to restoration of occlusal-restricted defect. Nevertheless, no statistically significant relationship was found between C-factor and direct composite restoration success rate. 
TABLE 5. Correlation between USHPS parameters, including retention, marginal discoloration, and marginal adaptation, and different C-factor interpretations

\begin{tabular}{|l|c|c|c|c|c|c|c|}
\hline Parameters & \multicolumn{2}{c}{ Retention } & \multicolumn{2}{c}{ Marginal discoloration } & \multicolumn{3}{c|}{ Marginal adaptation } \\
\hline C-factor as the ratio of bonded and un-bonded surfaces & $\boldsymbol{r}$ & $\boldsymbol{p}$-value & $\boldsymbol{r}$ & $\boldsymbol{p}$-value & $\boldsymbol{r}$ & $\boldsymbol{p}$-value \\
\hline C-factor as the ratio of bonded surface area to un-bonded surface area & -0.15 & $>0.05$ & 0.21 & $<0.05$ & -0.24 & $<0.05$ \\
\hline
\end{tabular}

TABLE 6. Correlation between USHPS parameters, including secondary, anatomic form, and surface texture, and different C-factor interpretations

\begin{tabular}{|l|c|c|c|c|c|c|c|}
\hline Parameters & \multicolumn{3}{c}{ Secondary caries } & \multicolumn{3}{c|}{ Anatomic form } & \multicolumn{3}{c|}{ Surface texture } \\
\hline C-factor as the ratio of bonded and un-bonded surfaces & $\boldsymbol{r}$ & $\boldsymbol{p}$-value & $\boldsymbol{r}$ & $\boldsymbol{p}$-value & $\boldsymbol{r}$ & $\boldsymbol{p}$-value \\
\hline C-factor as the ratio of bonded surface area and un-bonded surface area & 0.40 & $<0.05$ & 0.29 & $>0.05$ & 0.21 & $>0.05$ \\
\hline
\end{tabular}

However, due to the obtained results, C-factor in turn was associated with other parameters, which indirectly influenced composite restoration success prognosis.

Mondelli et al. demonstrated that impact of C-factor and composite volume on contraction forces within the structure of used materials depends on properties of these materials [36]. Such fact was considered in the current study, and the same resin composite material was applied for restoration of all analyzed prepared cavities. Furthermore, initial parameters of C-factor could be modified with different kind of build-ups using incremental techniques, as previously described [22].

Finite element analysis showed that restoration displacement within tooth structure demonstrated greater correlation with C-factor compared to restoration volume, while within glass, such association was reversed. This tendency was explained by influence of surrounding structure stiffness, but both volume and configuration factor influenced surface displacement and stress of bonded composite restoration [37]. Moreover, C-factor and restoration volume were considered as factors influencing level of cusp deflection with enough level of correlation [38]. Previous research demonstrated that C-factor influenced bonding connection to dentin, and in order to compensate such negative effect, dentists should use low shrinkage composite for cavities with high C-factor parameter [39].

In Braga's study, it was shown that cavity volume and cavity depth parameters greatly influenced depth of microleakage, while C-factor did not show statistically significant linear correlation with this factor Analogical findings were observed in the present study regarding clinical success restorations, with volume's derivates as cavity's height and depth demonstrating statistical associations with criteria of clinical success outcome, while $\mathrm{C}$-factor itself was not directly related with significant clinical impact on restorations service. In turn, C-factor was observed to show direct relation to the cavity depth
TABLE 7. Regressions between direct composite restoration success and patient-associated parameter

\begin{tabular}{|c|c|c|}
\hline Patient-associated parameter & Mean & Linear \\
\hline \multicolumn{3}{|l|}{ Age, years } \\
\hline $20-24$ & $22.6 \pm 1.4$ & $p>0.05$ \\
\hline $25-29$ & $27.3 \pm 0.8$ & $p>0.05$ \\
\hline $30-34$ & $31.5 \pm 1.8$ & $p>0.05$ \\
\hline \multicolumn{3}{|l|}{ Gender } \\
\hline \multicolumn{2}{|l|}{ Male } & $p>0.05$ \\
\hline \multicolumn{2}{|l|}{ Female } & $p>0.05$ \\
\hline \multicolumn{3}{|l|}{ Caries intensity } \\
\hline Low & $2.1 \pm 0.5$ & $p<0.05$ \\
\hline Moderate & $3.2 \pm 1.1$ & $p<0.05$ \\
\hline High & $4.9 \pm 1.4$ & $p<0.05$ \\
\hline \multicolumn{3}{|l|}{ Tooth type } \\
\hline \multicolumn{2}{|l|}{ Molar } & $p>0.05$ \\
\hline \multicolumn{2}{|l|}{ Premolar } & $p>0.05$ \\
\hline
\end{tabular}

and inverse relation to its' diameter [40]. That is why possible problems with composite restoration placed within deep cavities were related more to their depth than width, while in some situation, the effect of volume could be more relevant than the effect of $\mathrm{C}$-factor on restoration success rate [37].

In Watts and Satterthwaite study, not only C-factor, but also the mass of used composite material was considered to affect axial shrinkage phenomenon of a composite. Moreover, researches had shown the presence of statistically significant influence of configuration factor on shrinkage-stress per mass unit [26]. Within condition of low C-factor parameters (class V, C-factor $=1.57$ ), it was mentioned that cavity's geometry, as a factor that influence polymerization shrinkage stress, in some sit- 
uations, could possibly overcome the impact of C-factor and quantity of used composite material [41].

Specific analysis of class I and class II cavities within the current study was reasoned by the fact that such defects relate to the molars and premolars, which represent posterior group of teeth. Class III and IV defects relate to frontal group of teeth, which in turn are characterized with different functional pattern, and direct restoration service within these teeth biomechanically differentiate them from posterior teeth. Also, classes I and II cavities present greatest difference in C-factor values, which make them the most appropriate study model for evaluation of $\mathrm{C}$-factor impact on restoration success. Therefore, the purpose of using class I and II cavities was to unify primary clinical conditions during the course of the study and to identify clinically significant influence of different $\mathrm{C}$-values parameters on restoration prognosis. The results of the present study demonstrated that $\mathrm{C}$-factor values, quantified by the ratio of exact surface area of bonded cavity walls and un-bonded ones, outweigh $\mathrm{C}$-factor values obtained just by the quantity ratio of number between bonded and un-bonded surfaces. Such a tendency was represented differently in C-factor 5 and C-factor 2 groups, which could be clinically interpreted as follow:

- In class I cavities, dentist could preserve some occlusal part of tooth while widening preparation area, since further restoration with modern materials and bonding techniques prevent possible chipping and fractures of enamel and dentin regions that was unsupported after preparation phase. This approach is consistent with so-called 'mini-invasive' treatment protocol, and because of that, $\mathrm{C}$-factor calculated by ratio of surfaces area reached $5.26 \pm 1.12(p>5)$.

- In class II cavities, caries could extend beyond contact surfaces with their effect being spread over occlusal part in dentine structure, while keeping intact outer layer of superficial enamel; in such situation, the extend of preparation surface reasoned from biological point of view with prevention of secondary caries development. Because of that, $\mathrm{C}$-factor calculated by the ratio of surfaces area, reached the value of $2.83 \pm 0.87(p>2)$; moreover, the mean overall surface area of cavity in $\mathrm{C}$-factor 2 group overreached in C-factor 5 situation.

Teeth included in C-factor 2 group were characterized with greater mean volume after restoration procedure (not statistically significant), which potentially could be associated with initial greater space for restoration within the condition of teeth rebuilding. Analogical space was restricted during occlusal defect restoration by tooth-antagonist occlusion relation.

Due to the obtained statistical data, registered outcomes were not supporting any validated connection between C-factor itself and clinical success of direct composite restorations. On the other hand, geometrical derivates of the cavity, such as depth, height, and volume of cavity as a function of latter parameters, demonstrated statistically significant association with clinical success level of direct composite restorations. Therefore, not C-factor itself, but geometry of the cavity, with its' spatial configuration, surface area, volumetric characteristics, and tridimensional interrelations of cavity walls, could potentially be categorized as the variable that impact composite restoration success over 12 months monitoring.

Considering main aspects of the Ukrainian Forensic Odontology development, assessment of C-factor and cavity geometrical parameters primary to restoration placement could be classified as a step for further complex quality evaluation of dental care provision. Ignoring of C-factor and geometrical derivates of the cavity under the circumstances of pronounced decrease of restoration success, potentially could be weighted as a possible fact of dentist's neglect, even though the connection between these parameters need to be argumentatively proved during future in-depth analysis. Different methods of composite evaluation success and functioning conditions are continuously developing and improving. Except for the used clinical criteria, techniques, such as spectrometric analyses or acoustic emission analysis, could be effectively implemented into clinical practice for the purpose of non-destructive composite restorations evaluation $[42,43]$.

Limitations of the present study can relate to a relatively small study sample (overall 61 studied restorations), but design of the investigation is considered to be a pilot for future development within studies devoted to optimization of direct restoration placement organized by first author's affiliated University. Another limitation is the use of most clinically oriented approaches and technologies while studying complicated mechanism of composite restorations changes during 12 months of monitoring. Even though shrinkage and stress patterns of composite restoration justified the use of laboratorial and mathematic modeling technologies during scientific research, our primary aim was to assess the level of C-factor and cavity geometry clinical significance due to their impact on clinical success rate. Further research will include indepth analysis of strictly identified parameters as possible predictors or functional derivates of success and survival outcomes within greater composite restorations study sample in clinical and in vitro conditions.

\section{CONCLUSIONS}

Considering the obtained data, it can be resumed that C-factor itself, while being evaluated only clinically without the use of laboratorial equipment and detailed calculational algorithms, could not be interpreted as dominant predictor for restoration failure pattern after 1-year monitoring. Volumetric cavity parameters and cavity derivates, such as quantity of used composite and geometrical parameters of the prepared cavity, present greater influence on the outcome clinical success param- 
eters after 12 months of restorations functioning. Both class I (with C-factor > 5) and class II (with C-factor > 2) restorations demonstrate high level of clinical success after 12 months of service, according to USHPS evaluation criteria. Proposed investigation algorithm that included analysis of cavity and restorations digital scans within adapted software with restoration of volume and cavity's geometry objectification of C-factor, seem to be appropriate for the formulated research objective, and can be recommended for the use with analogical purposes.

\section{CONFLICT OF INTERESTS}

The authors declare no potential conflicts of interest with respect to the research, authorship, and/or publication of this article.

\section{References}

1. Alvanforoush N, Palamara J, Wong RH, Burrow MF. Comparison between published clinical success of direct resin composite restorations in vital posterior teeth in 1995-2005 and 2006-2016 periods. Aust Dent J 2017; 62: 132-145.

2. Bohaty BS, Ye Q, Misra A, Sene F, Spencer P. Posterior composite restoration update: focus on factors influencing form and function. Clin Cosmet Investig Dent 2013; 5: 33-42.

3. Beck F, Lettner S, Graf A, et al. Survival of direct resin restorations in posterior teeth within a 19-year period (1996-2015): a metaanalysis of prospective studies. Dent Mater 2015; 31: 958-985.

4. van Dijken JW. Durability of resin composite restorations in high C-factor cavities: a 12-year follow-up. J Dent 2010; 38: 469-474.

5. Opdam NJ, Bronkhorst EM, Loomans BA, Huysmans MC. 12-year survival of composite vs. amalgam restorations. J Dent Res 2010; 89: 1063-1067.

6. Ástvaldsdóttir Á, Dagerhamn J, van Dijken JW, et al. Longevity of posterior resin composite restorations in adults - a systematic review. J Dent 2015; 43: 934-954.

7. Correia AM, Bresciani E, Borges AB, Pereira DM, Maia LC, Caneppele TM. Do tooth-and cavity-related aspects of noncarious cervical lesions affect the retention of resin composite restorations in adults? A systematic review and meta-analysis. Oper Dent 2020; 45: E124-140.

8. Van de Sande FH, Collares K, Correa MB, Cenci MS, Demarco FF, Opdam NJ. Restoration survival: revisiting patients' risk factors through a systematic literature review. Oper Denti 2016; 41 (S7): S7-26.

9. Demarco FF, Collares K, Correa MB, Cenci MS, Morares RR, Opdam NJ. Should my composite restorations last forever? Why are they failing? Braz Oral Res 2017; 31 (Suppl 1): e56. DOI: 10.1590/1807-3107BOR-2017.vol31.0056.

10. Kubo S, Kawasaki A, Hayashi Y. Factors associated with the longevity of resin composite restorations. Dent Mater J 2011; 30: 374-383.

11. Ghavami-Lahiji M, Hooshmand T. Analytical methods for the measurement of polymerization kinetics and stresses of dental resin-based composites: a review. Dent Res J (Isfahan) 2017; 14 225-240.

12. Braga RR, Ballester RY, Ferracane JL. Factors involved in the development of polymerization shrinkage stress in resin-composites: a systematic review. Dent Mater 2005; 21: 962-970.

13. Opdam NJ, Collares K, Hickel R, et al. Clinical studies in restorative dentistry: new directions and new demands. Dent Mater 2018; 34: 1-12.

14. Luchynskyi MA, Pyasetska LV, Luchynska II, Basista AS, Rozhko VI. Indices of the dental caries intensity in individuals with different clinical variations of psychophysiological disadaptation. J Educ Health Sport 2018; 8: 446-450.

15. Chandrasekhar V, Rudrapati L, Badami V, Tummala M. Incremental techniques in direct composite restoration. J Conserv Dent 2017; 20: 386-391

16. Joseph A, Santhosh L, Hegde J, Panchajanya S, George R. Microleakage evaluation of Silorane-based composite and methacrylate-based composite in class II box preparations using two different layering techniques: an in vitro study. Indian J Dent Res 2013; 24: 148

17. Peyton JH. Finishing and polishing techniques: direct composite resin restorations. Pract Proced Aesthet Dent 2004; 16: 293-298.

18. Mopper KW. Contouring, finishing, and polishing anterior composites. Inside Dentistry 2011; 7: 62-70.

19. Celik C, Arhun N, Yamanel K. Clinical evaluation of resin-based composites in posterior restorations: 12 -month results. Eur J Dent 2010; 4: 57-65.

20. Michelinakis G, Apostolakis D, Tsagarakis A, Kourakis G, Pavlakis E. A comparison of accuracy of 3 intraoral scanners: a singleblinded in vitro study. J Prosthet Dent 2020; 124: 581-588.

21. Ammoun R, Bencharit S. Creating a digital duplicate denture file using a desktop scanner and open-source software: a dental technique. J Prosthet Dent 2020; 19: S0022-3913(20)30095-0. DOI: 10.1016/j.prosdent.2020.01.027.

22. Van Ende A, Mine AJ, De Munck J, Poitevin A, Van Meerbeek B. Bonding of low-shrinking composites in high C-factor cavities. J Dent 2012; 40: 295-303.

23. Macorra García JC, Gómez Fernández S. Quantification of the configuration factor in Class I and II cavities and simulated cervical erosions. Eur J Prosthodont Restor Dent 1996; 4: 29-33.

24. Wang R, Lagakos SW, Ware JH, Hunter DJ, Drazen JM. Statistics in medicine - reporting of subgroup analyses in clinical trials. $\mathrm{N}$ Engl J Med 2007; 357: 2189-2194.

25. Ho R. Handbook of univariate and multivariate data analysis and interpretation with SPSS. Chapman and Hall/CRC; 2006.

26. Watts DC, Satterthwaite JD. Axial shrinkage-stress depends upon both C-factor and composite mass. Dent Mater 2008; 24: 1-8. DOI: 10.1016/j.dental.2007.08.007.

27. Fu J, Aregawi WA, Fok AS. Mechanical manifestation of the C-factor in relation to photopolymerization of dental resin composites. Dent Mater 2020; 36: 1108-1114.

28. Almeida Junior LJ, Penha KJ, Souza AF, et al. Is there correlation between polymerization shrinkage, gap formation, and void in bulk fill composites? A $\mu$ CT study. Braz Oral Res 2017; 31: e100. DOI: 10.1590/1807-3107bor-2017.vol31.0100.

29. Cunha LG, Alonso RC, Neves AC, de Goes MF, Ferracane JL, Sinhoreti MA. Degree of conversion and contraction stress development of a resin composite irradiated using halogen and LED at two C-factor levels. Oper Dent 2009; 34: 24-31.

30. Han SH, Sadr A, Tagami J, Park SH. Internal adaptation of resin composites at two configurations: Influence of polymerization shrinkage and stress. Dent Mater 2016; 32: 1085-1094.

31. da Veiga AM, Cunha AC, Ferreira DM, et al. Longevity of direct and indirect resin composite restorations in permanent posterior teeth: A systematic review and meta-analysis. J Dent 2016; 54: 1-12. DOI: 10.1016/j.jdent.2016.08.003.

32. Arhun N, Celik C, Yamanel K. Clinical evaluation of resin-based composites in posterior restorations: two-year results. Oper Dent 2010; 35: 397-404.

33. Çelik Ç, Arhun N, Yamanel K. Clinical evaluation of resin-based composites in posterior restorations: a 3-year study. Med Princ Pract 2014; 23: 453-459.

34. Montagner AF, Sande FH, Müller C, Cenci MS, Susin AH. Survival, reasons for failure and clinical characteristics of anterior/ posterior composites: 8-year findings. Braz Dent J 2018; 29 : 547-554.

35. Chrysanthakopoulos NA. Reasons for placement and replacement of composite dental restorations in an adult population in Greece. Acta Stomatol Croat 2010; 44: 241-250. 
36. Mondelli RF, Velo MM, Gonçalves RS, Tostes BO, Ishikiriama SK, Bombonatti JF. Influence of composite resin volume and C-factor on the polymerization shrinkage stress. Braz Dent Sci 2016; 19: 72-81.

37. Boaro LC, Brandt WC, Meira JB, Rodrigues FP, Palin WM, Braga RR. Experimental and FE displacement and polymerization stress of bonded restorations as a function of the C-factor, volume and substrate stiffness. J Dent 2014; 42: 140-148.

38. Lee MR, Cho BH, Son HH, Um CM, Lee IB. Influence of cavity dimension and restoration methods on the cusp deflection of premolars in composite restoration. Dent Mater 2007; 23: 288-295.

39. Singh TV, Patil JP, Raju RC, Venigalla BS, Jyotsna SV, Bhutani N Comparison of effect of c-factor on bond strength to human dentin using different composite resin materials. J Clin Diagn Res 2015; 9: ZC88-ZC91.

40. Braga RR, Boaro LC, Kuroe T, Azevedo CL, Singer JM. Influence of cavity dimensions and their derivatives (volume and ' $\mathrm{C}$ ' factor) on shrinkage stress development and microleakage of composite restorations. Dent Mater 2006; 22: 818-823.

41. Borges AL, Borges AB, Xavier TA, Bottino MC, Platt JA. Impact of quantity of resin, C-factor, and geometry on resin composite polymerization shrinkage stress in Class V restorations. Oper Dent 2014; 39: 144-151.

42. Gu JU, Choi NS. Evaluation of marginal failures of dental composite restorations by acoustic emission analysis. Dent Mater J 2013; 32: 398-404.

43. Kostenko S, Dzupa P, Levandovskyi R, Bun Y, Mishalov V, Goncharuk-Khomyn M. Optimized approach of dental composites identification with the use of original spectrophotometric algorithm. J Int Dent Medical Res 2018; 11: 403-408. 